\title{
LA NARRATIVA DOMINICANA CONTEMPORANEA: EN BUSCA DE UNA SALIDA
}

POR

\author{
MARGARITA FERNANDEZ OLMOS \\ Brooklyn College, CUNY
}

Fénix. Ave fabulosa consumida en fuego que renace de: sus propias cenizas; la restauración, renovación o renacimiento después de la ruina o destrucción.

«El largarse de aquí es como una epidemia, Pérez. Mira, los primeros síntomas de la enfermedad comienzan desde la infancia» [Curriculum (el sindrome de la visa)].

«-Sí, pero no es eso, no es eso a lo que yo me refiero: - dijo Freddy-. A mí lo que me molesta es la isla, el aislamiento, lo aislado que uno está aquí. Uno está como. enterrado vivo aquí.

-Yo no lo veo así - dijo Wilson-. Pero, de todas maneras, lo importante no es que tú te vayas, no es que nos vayamos todos. Lo importante es que regresemos algún. día. ¿No te parece?» [Sólo cenizas hallarás (bolero)].

La narrativa dominicana reciente puede considerarse como una literatura de indagación por parte de autores que intentan captar, diagnosticar y analizar una realidad histórica en crisis. Como en otras culturas latinoamericanas, en la República Dominicana el escritor cumple un papel importante en la delimitación y legitimación de valores que se identifican con la cultura nacional. Por eso, las novelas producidas desptués de la muerte de Trujillo, y particularmente las que surgen con posterioridad a la frustrada revolución de abril de 1965 (cuando las tropas norteamericanas intervienen e impiden la cristalización de las aspiraciones constitucionalistas), toman una dirección introspectiva al buscar los motivos de la crisis actual. Comparte con otros países latinoamericanos el hecho de ser una «literatura de derrotados», según la definición de Angel Rama: 
El período en que la acción sólo dejaba sitio para la consigna es seguido por otro en que la reflexión, la explicación, la reviviscencia de lo vivido, el testimonio del sufrimiento, se traducen en productos literarios... una comunidad se explica largamente y se reencuentra.

Es una literatura de derrotados. Ya alguna vez se observó que las derrotas nos han dotado de obras tanto o más importantes que las victorias, quizás porque exigen un esfuerzo más tenaz y conducen a los límites mismos de la literatura. Una literatura de derrotados no es forzosamente una renuncia al proyecto transformador, sino una parénesis interrogativa. La perspectiva desde la cual el escritor puede hablar dispone del mínimo reposo indispensable y los sucesos pasados pueden percibirse ya conjuntamente, detectando su coherencia y su significado. Este período puede ser, artísticamente e intelectualmente, aún más proficuo que el representado por la anterior literatura militante ${ }^{1}$.

Dos novelas de este período, Sólo cenizas hallarás (bolero) (1980) ${ }^{2}$, de Pedro Vergés, y Curriculum (el sindrome de la visa) (1982) ${ }^{3}$, de Efraím Castillo, nos ofrecen interesantes ejemplos de obras en las que la búsqueda de una salida - literaria, política y personal- organiza el discurso y las estrategias narrativas. A pesar de sus diferencias, ambas novelas tratan de un tema que, aunque presente en obras anteriores, ha cobrado interés en los últimos años, en vista de los cambios socioeconómicos del país: uno de ellos, el de la emigración/exilio. En los años sesenta y setenta aumenta la migración interna desde los campos a las ciudades y particularmente a la capital dominicana, como resultado del crecimiento de la población, la expansión de la industria liviana y el atraso agrícola; la emigración externa crece también enormemente, resultando en la «diáspora» dominicana estudiada por Hendricks y otros ${ }^{4}$. Mientras la gran mayoría de los emigrantes salieron por motivos económicos, es también cierto que, dada la situación de dependencia económica y la política de los países latinoamericanos frente a Norteamérica, la distinción entre exilio y emigración desaparece:

El exiliado no es ya el ciudadano expulsado de la patria ... sino el que abandona voluntariamente su tierra, a veces para evitar persecu-

1 «Founding the Latin American Literary Community», trad. de Pamela Pye, en Review, 30 (septiembre-diciembre 1981), p. 13. Le agradezco a Luis Harss el haberme facilitado la versión original de este ensayo.

${ }^{2}$ Valencia: Editorial Prometeo, 1980. En adelante citaremos por esta edición.

${ }^{3}$ Santo Domingo: Editora Taller, 1982. Las citas corresponden a esta edición.

${ }^{4}$ Cfr. Glenn C. W. Ames y Tom Sprouse, «Internal Migration and Unemployment in the Dominican Republic», en Revista/Review Interamericana, XI, 3 (otoño 1981), pp. 387-398; Glenn Hendricks, Los dominicanos ausentes: un pueblo en transición, trad. de Eduardo Villanueva (Santo Domingo: Editora Alfa y Omega, 1978). 
ción, prisión o muerte, con más frecuencia para continuar su tarea propia en país con condiciones más propicias... Vistas las raíces profundas de la masificación migratoria contemporánea, como la nueva concepción del exilio, se comprende que se esfumen las rígidas fronteras trazadas entre ambos fenómenos ${ }^{5}$.

En la República Dominicana y en las otras islas del Caribe, sujetos a la alienación cultural constante del neocolonialismo, el exilio de la clase profesional y del intelectual o artista encierra motivos y características aún más complejas, como bien lo señala el poeta guyanés Jan Carew:

El escritor caribeño es hoy una criatura en equilibrio entre el limbo y la nada, el exilio en el extranjero y la falta de una patria en su país, entre el pueblo por un lado y el criollo y el colonizador por otro. El exilio puede ser voluntario o puede ser impuesto por la fuerza de las circunstancias... El celo colonial del europeo hizo de los indígenas exiliados en sus propios países... El escritor caribeño, al irse al extranjero, busca, de hecho, poner fin a su exilio ${ }^{6}$.

Hasta ahora no se ha producido en la República Dominicana una amplia literatura de la experiencia de la inmigración, como en Puerto Rico; sin embargo, la influencia de los dominicanos «ausentes», la penetración cultural norteamericana y la siempre presente opción de la emigración como solución a los problemas individuales o colectivos, sí han sido explorados en la narrativa contemporánea. En la novela Curriculum (el síndrome de la visa), por ejemplo, la alienación cultural del protagonista forma el meollo del asunto. Como en las novelas de Manuel Puig, la penetración del mundo cultural norteamericano a través de la cultura popular, y particularmente del cine y la televisión, margina al protagonista de la sociedad en que vive. Castillo parece compartir las ideas de Carlos Monsiváis: «We derive from dreadful and glorious movies. Against the unreality of our lives we have called upon the severe realism of dark theaters. We have based our world view on images» ${ }^{7}$. Desde el epígrafe - «nos venden sueños en technicolor y a 525 líneas. Entonces, ¿qué más quieren?»- a las referencias constantes, en la novela, a artistas e imágenes de Hollywood, Curriculum... atribuye la culpa de la situación social dominicana a su marginación cultural y económica. Esta idea es acompa-

\footnotetext{
${ }^{5}$ Rama, op. cit., p. 11, nota 1.

6 "El escritor caribeño y el exilio», en Casa de las Américas, VIII, 105 (noviembre-diciembre 1977), p. 38.

${ }^{7}$ «Pop Culture and Literature in Latin America», trad. de Lydia Hunt, en Review, 34 (enero-junio 1985), p. 12.
} 
ñada y subrayada por múltiples recursos literarios que siguen de cerca las técnicas cinematográficas y las del mundo de la publicidad comercial, que Efraím Castillo, como miembro de esa profesión, conoce íntimamente. Así, pues, el lenguaje es rápido y agresivo, con largos pasajes de juegos de palabras y mensajes cortos; Castillo intenta combinar el análisis histórico y la ficción con el discurso explosivo, persuasivo y, a veces, disonante de los medios de comunicación masiva.

La trama de la novela refiere los problemas de Alberto Pérez, un intelectual que milita en un partido de izquierda, en su afán de conseguir lo que él considera la única salida a sus problemas económicos y personales: una visa norteamericana. La obra revela, a través de las palabras del protagonista, su rechazo, por un lado, de la política estadounidense, y por otro, su fascinación por la cultura de ese país.

Fíjate, si hubiese estado no-penetrado, habría escogido Venezuela, por ejemplo, o Méxíco, el mero México, o la Argentina... Pues, como te iba diciendo, escogí los EE. UU. porque Sí, porque me atraía todo (pp. 48-49).

También comparte con Carew la idea del exilio en el Caribe como otra forma de la migración, ya que se trata de países dependientes de los Estados Unidos.

¿Qué somos nosotros, Boris? Una colonia. Aquí los norteamericanos mantienen parte de sus excedentes de capital financiero. Trabajar en publicidad, por ejemplo, aquí, es igual a trabajar publicidad allá. Cuando aquí se anuncia el aceite El Manicero se está anunciando un aceite norteamericano, porque la mayor parte del aceite que contiene una lata de aceite El Manicero se llena con aceite proveniente de allá, de los Estados Unidos. Y así sucede con casi todos los productos que consumimos... Entonces, ¿qué más da trabajar aquí que allá, máxime si tengo una familia, incluyéndote a ti, que mantener, que levantar, que sacar a flote para que vea el derrumbe definitivo de este imperio que ya va para sus cien años? (p. 158).

E1 protagonista, «un pequeño burgués intelectual» (como la mayoría de los escritores dominicanos), es un hombre idealista, individualista y honesto; es también machista y egoísta, y, por lo mismo, una figura anacrónica, destinado al fracaso. No nos sorprende verlo empujado inexorablemente hacia su propia destrucción sin haber logrado su meta original, sino descubriendo otra salida, aún más trágica, a su situación. La obra es una crítica y una autocrítica (Castillo se incluye como uno de sus per- 
sonajes) de una clase social y de su concepción política y filosófica, cuyos «errores de apreciación histórica» pretende corregir.

El recurso temático de la búsqueda de la visa ofrece numerosas oportunidades para desviarse del hilo narrativo y postular una serie de argumentos, que varían desde sus ideas sobre la historia dominicana, los errores de los partidos de izquierda, las relaciones entre los hombres y las mujeres y la creación artística, hasta la influencia de la publicidad. Sus reflexiones históricas, las más comunes, suelen representarse con palabras o frases cortas, episodios reconstruidos para producir ciertos efectos; se saltan varios siglos, se comprimen y se reducen a mensajes o slogans. Crea, así, una sensación de movimiento rápido, y como el lenguaje de la publicidad, deja una impresión duradera.

¿Adónde diablos piensas llegar? Bueno, no es adónde pienso llegar, sino dónde estamos. Hablamos de lugares, apacibles. Con ríos. Arroz. Plátanos. Condición de fuga. De fugar. ¿Transfugar? Ah, atravesar la fuga. ¿Tránsfugas? ¿España?... La duración aquí. Los colonizadores en. Por. Para. Rajadura. ¿De abrirse una grieta? De rajarse: como Jalisco. ¿Espanto, quebranto, Lepanto? Todo junto: susto, enfermedades, cobardía. Las flechitas primero; ciclones, terremotos, después; los piratas, mucho después; el 63, Luperón y los otros, mucho-más-después (pp. 11-12).

El pasado en cañuelas doradas, como para reírse; el futuro en cañuelas (¿cómo las ponemos, compadre, negras?), bueno, dejemos las cañuelas del futuro para ponerlas en cañuelas doradas cuando sea posible y todo se contemple con la objetividad dialéctica conque nos tienen desacostumbrados. ¿Duarte? En cañuelas doradas, of course. ¿Sánchez? En cañuelas doradas, à bien tout. ¿Mella? En cañuelas doradas, ecco. ¿Lilís? ¡Eh, un momento, no me juegues con Lilís! ¿Oístesssssssss? ¿Trujillo? ¿Qué es esto, un gancho... ganchitos a mí? iNo me jodas! (pp. 78-79).

Las teorías no se limitan a las del protagonista; su encuentro imprevisto con un remador elocuente le sorprende con un discurso sobre el proceso histórico en la República Dominicana.

¿Paranoia! iEsa es la palabra! Creo que es algo histórico, algo que está latente y que posiblemente crezca con todas las frustraciones que les acontecen. ¿Desde cuándo viene todo? ¿Desde Sánchez Ramírez? ¡No, desde más atrás! Tiene que ver con el abandono de España... ino, desde antes! Tiene que ver con el exterminio de los indios, con el cruce con los negros, con los ataques piratas, con los ciclones y terremotos, con el crecimiento de la parte francesa, con la independencia efímera, con la dominación haitiana, con las cuitas de Duarte, con la anexión de Santana, con los líos de Luperón, con Báez, con Lilís, con Mon Cáceres, con la intervención del 16, con la autonecesidad de Horacio, con la subi- 
da de Trujillo, con los desembarcos fallidos, con el propio ajusticiamiento de Trujillo que la CIA piloteó y, ahora, ahora recientemente, con la caída de Bosch y la muerte de Tavárez Justo. Eso es lo que deseo que entienda, no es cuestión de acechar a quién, sino de quién acecha a uno (p. 91).

Las referencias a personas e incidentes del mundo dominicano son inaccesibles al lector no familiarizado íntimamente con esa realidad. E1 protagonista menciona, en varios lugares, por ejemplo, a los escritores de los años sesenta que abandonaron la literatura y, según él, las ideas progresistas para integrarse al mundo comercial y lucrativo de la publicidad. Uno de los personajes de la novela, Monegal, tienta a Pérez con los beneficios de su empresa publicitaria, pidiéndole que trabaje con él y deje la lucha política y sus planes de emigrar. Para Pérez, un padre de familia, la tentación es grande; sin embargo, rechaza la oferta y aprovecha la situación para criticar a los artistas (incluyendo al autor mismo) que no fueron firmes en sus propósitos.

-Ahora es que este negocio se pondrá bueno, Beto. Es tu oportunidad para entrar en él. Antes de la revolución entró Efraím Castillo. Tú tienes más talento que él, vales más que él, a pesar de que ambos son individualistas. Estamos tentando a otros. René del Risco. Iván García. Ellos valen, Beto. Proceden de partidos de izquierda, del teatro... Lo observaba en los ojos; le mencionó la deserción de Castillo hacia la publicidad, sacrificando su talento, su amor a la revolución; le habló del futuro enganche de René, de Iván, de Miguel Alfonseca-. Hay que entrar en órbita, Beto. Antes de la revolución te ofrecía una sociedad; ahora te ofrezco un empleo (p. 200).

Si las alusiones, en la novela, a personajes de la realidad dominicana limitan su público lector y la convierten en una obra «marginal», también hay que destacar que uno de sus temas básicos es la dominación cultural, y, como tal, su propósito fundamental es el de declarar la singularidad de la cultura dominicana frente a la impuesta. Reconoce, pues, la tarea imprescindible de enarbolar un sentido de la cultura que valorice lo específico y original de cada uno de los países latinoamericanos, sin ignorar lo que tienen en común. Es una situación que guarda relación con las ideas de Angel Rama sobre el nuevo regionalismo en América Latina:

Si el factor histórico puede ser bastante semejante en las diversas regiones interiores latinoamericanas, en la medida en que responde a la pulsión universal de la hora, a los niveles adquiridos por las metrópolis externas para su penetración ecuménica, en cambio la composición cul- 
tural regional manifiesta una alta especifidad y una particularidad que difícilmente se rinden a las taxonomías que proponen sociólogos o economistas... Lo original de cualquier cultura es su misma originalidad, la imposibilidad de reducirla a otra, por más fundamentos comunes que compartan ${ }^{8}$.

La lucha del protagonista por salir de la marginalidad impuesta por la sociedad en que vive puede compararse con los intentos de la narrativa dominicana contemporánea de encontrar una salida al aislamiento impuesto a las literaturas de la «periferia», tanto por su relación de dependencia con Norteamérica, como con la que mantienen con los grandes centros culturales hispanoamericanos, que ignoran, en gran parte, su producción. La justa lucha, por parte de los países pequeños y marginados, de reclamar el lugar que les corresponde dentro de la tradición literaria hispanoamericana, se asemeja a la de las «regiones internas» o culturas tradicionales frente a la cultura de los grandes urbes: ambos casos implican la defensa y afirmación del discurso tradicional o local, sin caer en lo estático o defensivo. Escribir una obra de aceptación universal, sin renunciar a lo particular y propio, supone un equilibrio similar al requerido por las culturas nacionales frente al impacto modernizador: «La modernidad no es renunciable, y negarse a ella es suicida; lo es también renunciar a sí mismo para aceptarla» ${ }^{9}$. Y aunque la marginalidad del intelectual, el neocolonialismo y el imperialismo cultural no son temas exclusivos de la República Dominicana, relacionarlos con lo específico del mundo dominicano excluye pretensiones universalistas, particularmente al recordar que un aspecto importante de la obra es el de definir, aceptar o rechazar los valores nacionales que condujeron al país a su estado actual.

¿Sería Trujillo una síntesis dialéctica? Trujillo resumía todos los vicios y virtudes de nuestro país. Mujeriego, parrandero, amante de los caballos y bebedor. Se acostaba temprano y se levantaba con el alba. Buen amigo de los amigos y enemiguísimo de los enemigos. ¿Qué hubiese sido de Trujillo de haber nacido en una sociedad más avanzada? En la alemana, por ejemplo. ¿Hubiese sido igual que Hitler, que Mussolini? De Trujillo estar vivo, en buena salud, joven, habría dado un golpe de estado con la situación actual. Y entonces la gente caminando por ahí como si tal cosa; la gente yendo y viniendo con sus penas a cuestas, con sus alegrías recortadas como el presupuesto doméstico, todo en rojo (p. 141).

${ }^{8}$ Transculturación narrativa en América Latina (México: Siglo XXI, 1982), p. 97.

${ }^{9}$ Rama, Transculturación narrativa..., p. 71. 
Al enumerar los «vicios y virtudes de nuestro país», que, según el protagonista, resumía Trujillo, se nos hace difícil distinguirlos en vista de su propio comportamiento y los recuerdos de su amigo Vicente:

E1 [Beto] era como parte de esta tierra. Un raro, sí. Pero parte de esta tierra. El mixturaba todo: mulato, cobarde, valiente, mujeriego, nojugador pero creyente de las cábalas... No, sabía que jamás saldría del país (p. 323).

Si el ser mujeriego es considerado una virtud (y ¿por qué no llamar entonces a Trujillo un abusador en ese contexto?), Beto Pérez es un virtuoso ejemplar. Desde el comienzo del libro, cuando sale de la cárcel, hasta su muerte, tiene múltiples relaciones con mujeres, que lo aceptan sin condiciones, incluyendo a su esposa, a quien golpea y maltrata sin remordimiento:

iAy si la vieras a mi mujer, Isabel! Posiblemente no la reconozcas. Ha cambiado terriblemente, hace lo que yo quiera y creo que ése ha sido el éxito de mi matrimonio y de todos los matrimonios que han durado en la faz (o sobre la faz) de la tierra, que la mujer obedezca al hombre en todo... Pues ella me aguanta golpes, pero no golpes sádicos de mi parte sino golpes por la situación... todos estos cariños se deben, indefectiblemente, a que hay por el medio la cuestión del puchingbag, el asunto de las aguantaderas sin la cuestión de la liberación por medio porque ¿tú crees que el hombre y la mujer son iguales? ¿En el cerebro? Tal vez algo. Pero. ¿De verdad lo crees? (pp. 162, 165).

Y si la penetración cultural lo obsesiona, también la pene-tración sexual juega un papel fundamental y casi exclusivista en sus relaciones con $\mathrm{mu}-$ jeres, que suelen ser un estorbo o desvío de sus metas:

Y la palabra penetración le huele a la humedad vaginal de Julia. Pérez consigue una erección de apoteosis, de película en technicolor. Entonces abre la cremallera, saca el falo y se lanza contra Julia, que emite un chillido de placer, como el de miss Ramírez en la mañanita (pp. 24-25).

De la poca estimación que tiene hacia las mujeres no se escapa ni la figura histórica de la india Anacaona - la única figura femenina que destaca-, pues en el cuadro imaginario que se inventa del país la coloca «a la mítica, ¿tetuda?, buenahembra y esplendente Anacaona levantándose su falda de penca-e-coco y enseñando un cachito de sus bronceadas nalgas, y, entonces, ¡lo sensacional, lo sabroso!: unas cañuelas doradísimas» (p. 79). 
La actitud del protagonista con respecto a las mujeres refleja, en parte, sus propios «errores de apreciación histórica», y es obviamente una crítica del autor al revolucionario pequeño burgués, cuyos resabios machistas lo arrastran hacia posiciones inadecuadas. Así, también, el final de la obra, donde Beto debe decidir entre traicionar sus principios para obtener la visa o mantener sus posiciones, revela la idea de que, para haber cambios en el país, los valores representados por un Beto Pérez deben, como el mismo personaje, eliminarse. Pérez se cita con el cónsul norteamericano y, recordando escenas históricas de las relaciones de poder entre los EE. UU. y la R. D. (infiriendo que el conocimiento histórico conlleva la acción política), mata al cónsul y se suicida. Es el acto de un mártir, a la vez heroico, desesperado e inadecuado a las necesidades revolucionarias del país.

La ironía, como recurso narrativo, se revela de dos maneras fundamentales al final de la obra: la social y la personal. La ironía social se aprecia en las entrevistas con los amigos y familiares de Pérez, donde observamos que sólo con su ausencia pueden crecer y cambiar ciertas personas a su alrededor, las mujeres, su esposa y su hija, quien dice que su padre «fue parte de un presente que se extingue; un presente que no será pasado tumultuoso, estúpido, como el pasado que vivimos en este presente» (p. 333). Apreciamos también la ironía personal del protagonista, cuya búsqueda por la integridad resulta en el reconocimiento de ser un «obsoleto» social, destinado a desaparecer; y el hecho de que sólo con su muerte pudo asegurarse, después de dedicar tanto esfuerzo en buscar una salida, el fin de su exilio y la residencia permanente en su tierra.

En contraste con Curriculum, que analiza un caso individual, Sólo cenizas hallarás (bolero) se puede caracterizar como un estudio del autoengaño colectivo. El título, tomado de los versos de un bolero, señala una vertiente melancólica y nostálgica de la obra. Al contrario de otra obra caribeña, La guaracha del Macho Camacho ${ }^{10}$, que también se apropia de la música popular, pero con fines más irónicos (la guaracha repite insistentemente «la vida es una cosa fenomenal»), el título de Sólo cenizas... es fiel a su contenido; en la obra, el lector descubre «unas vidas que, en definitiva, están abocadas, como ese mismo verso presagia, a ser cenizas de la historia y de la vida» ${ }^{11}$.

${ }^{10}$ Luis Rafael Sánchez, La guaracha del Macho Camacho (Buenos Aires: Ediciones de La Flor, 1976).

${ }^{11}$ Cita proveniente de la portada de la edición mencionada en la nota 10. 
Sólo cenizas hallarás... es la primera novela, publicada, de Pedro Vergés. Adquirió difusión y prestigio por haber ganado el «Premio Blasco Ibáñez» en España (1980). Es una de las novelas dominicanas más interesantes de los últimos años por varias razones, entre ellas su logrado intento de romper con ciertos patrones culturales y su visión abarcadora y amplia de la experiencia histórica colectiva, la cual se refleja tanto en su manera de configurar el discurso narrativo como en el drama individual de sus personajes.

La obra abarca la época posterior a la muerte de Trujillo - concretamente desde diciembre de 1961 a diciembre de 1962- y refiere las aspiraciones y desengaños de la nación a través de unos personajes que intentan rehacer sus vidas después de treinta y un años de represión y aislamiento. La desaparición del patriarca los sumerge en crisis y cambios, y la trama se basa en la manera en que cada uno sale del caos que lo rodea. Para algunos, la salida se encuentra en la emigración/exilio (Freddy Nogueras y Yolanda Martínez); para otros consiste en planes quijotescos para un futuro desconocido en un presente que falta por conocer (el teniente Sotero de los Santos y Lucila, la sirvienta), y para el personaje que comparte la narración con el narrador omnisciente (Altagracia Valle) la salida personal consiste en reconstruir nostálgicamente el pasado y tratar de comprenderlo.

Debe destacarse que la estructura de la novela es a la vez lineal y entrecruzada; es decir, que cada capítulo se dedica a uno de los personajes y se interrumpe en el próximo para presentar a otro. El resultado es, por ejemplo, que el primer capítulo abre con la historia de Feddy Nogueras y su madre, Altagracia Valle, el día 11 de junio de 1962 (todos los capítulos llevan nombre y fecha); va seguido por el segundo capítulo y la historia de Yolanda Martínez, de diciembre de 1961 a marzo de 1962. La historia de Freddy se encuentra de nuevo en el capítulo seis, donde se retoma el hilo del relato interrumpido al final del primer capítulo. Así se suspenden e intercalan las historias individuales, sucesivamente, hasta el final, donde Freddy parte para Nueva York. Esta manera de estructurar la obra no sólo interrumpe el hilo de la narración, sino que, frecuentemente, lo va replanteando y reinterpretando desde otra perspectiva, produciéndose así una novela de variadas y múltiples resonancias.

Los cinco personajes principales mencionados arriba y otros personajes menores son de las clases «trepadoras» o aspirantes (o, por lo menos, es así como la obra los representa): la pequeña burguesía y el campesinado. Sus reacciones a la vida varían según su experiencia y clase social, y también según su interés o conocimiento de la realidad que les rodea. Freddy, por ejemplo, es un estudiante universitario con ideas pro- 
gresistas, pero también con un pesimismo total sobre su futuro en el país. Cree que su única salida es la emigración:

Y en más de una ocasión llegó a desear con rabia, con ilusión incluso, que tal cosa octurriera, que el país estallara en pedazos y que se deshiciera de una maldita vez esa especie de falso regocijo que lo inundaba todo de una manera amarga y melancólica. Pero de sobra sabía que nunca sería hoy, que jamás surgiría semejante oportunidad y que los que eran como él no tenían más remedio que largarse o joderse o pegarse un plomazo en la cabeza. Eso o tomar conciencia, como decía Paolo con su cara de iluminado moralista: más iluminado cuanto más obtuso, persistente y cerrado se iba haciendo el absentismo político de Freddy (p. 16).

Yolanda es una dominicana «ausente» que regresa al país por complicaciones amorosas en Nueva York. Sus valores como mujer de clase media no impiden que disfrute de la liberación sexual y personal que la emigración le brinda. En la República Dominicana trata limitadamente de adaptarse de nuevo al papel de mujer tradicional. Fracasan estos intentos, sin embargo, y, dándose cuenta de la incompatibilidad de sus acciones con sus verdaderos sentimientos, regresa felizmente a la «libertad» del exilio. El teniente Sotero de los Santos es un militar sin vocación, quien cree encontrar la solución a sus problemas económicos y sociales en un matrimonio de conveniencia con una muchacha de «buena familia». Su ignorancia política y económica, y su naturaleza escéptica, lo conducen al fracaso de sus planes matrimoniales y comerciales. "Lucila, la sirvienta», es una campesina que sueña con mejorar su vida en la capital y, como el teniente, cree que con las buenas apariencias y una firme determinación podrá realizar sus deseos de ascenso social. A diferencia de él, sin embargo, convierte la derrota en victoria personal. $Y$ «Altagracia Valle, viuda de Nogueras», rellena los espacios olvidados; cuenta detalles de los otros personajes, ofreciendo otra versión de los eventos, mientras recrea su pasado con el padre de Freddy y los demás.

En esta novela, la perspectiva respecto a la emigración/exilio es diferente a la anterior, quizá debido a la propia experiencia del autor. Vergés ha pasado muchos años en el extranjero (España) y, sin duda, esto se refleja en sus personajes:

- Haces bien en irte, Freddy, haces muy bien - dijo Yolanda.

-Yo creo que me fuera de todas formas, con muertos y sin muertos. Yo creo que uno no entiende este país hasta que no se aleja de él -filosofó Freddy, repantingado, desde el fondo de su momentánea indolencia.

- Si - dijo Wilson-. Lo malo es que después lo comprende tan bien que ya no hay quien te haga regresar. 
—Eso no es cierto - terció Evelinda-. Hay mucha gente que vuelve.

-Y que vuelve a ir -insistió Wilson, rebosando patriotismo de signo negativo-. En cuanto tú sales de aquí ya no hay manera. Te conviertes en una pelotica de pingpong saliendo y entrando (p. 295).

Para Freddy, la salida a Nueva York es un viaje que «se efectuaba hacia un lugar secreto, tal vez desconocido, de sí mismo», mientras que para Yolanda es un «viaje de regreso, que era la única vía de escape, la única solución que encontraba para su problema». Hay que recordar que la vida de estos personajes en la metrópolis no es la de la mayoría de los inmigrantes: "Yolanda, en Nueva York, vivía de lo más bien y ganaba bastante en una compañía exportadora», y, según otro personaje, Freddy «ya sabía inglés, que trabajaba en una factoría, que por la noche iba a la escuela», es decir, que no es la vida alienante e insegura de los miles de «ilegales» o indocumentados dominicanos que trabajan en condiciones pésimas en la ciudad.

El personaje de Yolanda representa una nueva visión de la mujer dominicana, luchando por romper con su papel tradicional y las contradicciones internas que la transición hacia la liberación siempre conlleva. La independencia económica y personal que experimenta en Nueva York le ayuda a reconocer su valor y también a reorganizar su vida después de su fracaso amoroso en Santo Domingo. Mientras en Curriculum... los personajes femeninos - la esposa y la hija de Beto Pérez- no se liberan hasta la desaparición del protagonista, en Sólo cenizas hallarás... Yolanda y Lucila se dan cuenta de su capacidad y fuerza, a pesar de la presencia de los hombres. Indudablemente, la emigración/exilio ayudó a inspirar esa confianza y seguridad en Yolanda; los golpes de la vida hicieron 10 mismo en Lucila. Vergés demuestra una capacidad, poco común en los escritores dominicanos, de penetrar la conciencia y la perspectiva femenina en la literatura. El resultado es una de las más logradas representaciones femeninas en la narrativa dominicana.

Del mismo modo, Lucila, la sirvienta campesina, es un personaje en movimiento; emigra, desde el campo que detesta, a la ciudad para dejar de ser "campuna» y lograr el éxito, «que para eso era indiecita clara, no negra ni bembona». También como los otros, vacila entre el optimismo ciego y el fatalismo, y, al igual que el teniente Sotero, no tiene ideas políticas propias, sino las de sus patrones y los amigos de ellos que simpatizan con la UCN (Unión Cívica Nacional, el partido de la oligarquía dominicana a raíz de la muerte de Trujillo). Su conciencia femenina y política se desarrolla progresivamente después de perder su trabajo y quedar embarazada del teniente Sotero. Decide regresar al campo, pero ya sin 
las ilusiones falsas y alienantes de antes. Como en el caso de Yolanda, el rechazo de un hombre crea conciencia y determinación. Su perspectiva política cambia, también, hacia direcciones más apropiadas a sus intereses.

En cuanto pariera Lucila sabía bien lo que tenía que hacer, salir del campo sola, dejarle el muchachito a su mamá y buscarse la vida como fuera. No de sirvienta, no, sino de cualquier cosa en que ganara cuartos bien rendidos y que le permitiera sacar a toda su familia, empezando por él, su muchachito, de aquella porquería de casa en que habitaban. Nada de eso sería ahora difícil, que el 20 de diciembre se celebrarían por fin las dichosas elecciones y por fortuna no iban a ganar ellos, los tutempotes, los como el señor Flores y esa gente, sino que iban a ganar el PRD y Juan Bosch, con lo cual dentro de muy poquito iba a tener trabajo todo el mundo: la gente y ellos mismos lo decían... Ella ya estaba decidida a hacerle frente a su existencia sola, con empuje y con fuerza, no pensaba pasarse el día entero quejándose y quejándose. Todo eso se lo decía y se lo repetía sin parar Lucila, la sirvienta, que ya no lo sería jamás de los jamases... (pp. 404-405).

E1 personaje de Lucila no sólo es interesante desde el punto de vista feminista, sino también por el hecho de ser campesina y romper con los modelos pasivos tradicionales de este sector de la población. Rechaza la dirección política autoritaria de sus patrones y toma las riendas de su vida y la del hijo o hija que nacerá: la esperanza de un futuro desmitificado y con lúcida conciencia de sus objetivos.

Si la desgracia inspira el propósito y la firmeza de Lucila, éste no es el caso del teniente Sotero de los Santos, el más trágico de los personajes. Su tragedia consiste precisamente en su «tenaz... afán de mantenerse al margen» de lo que ocurre en el país y aferrarse a planes e ideas que no concuerdan con las condiciones objetivas de la nación. Reconoce, sí, que al morir Trujillo y salir los herederos del régimen, «no pasaría mucho tiempo antes de que los otros consideraran que la hora de edificar sus mansiones y de adquirir sus fincas había, por fin, llegado» (p. 76), pero se imagina ser un joven Ford o Rockefeller dominicano e ignora las consecuencias del subdesarrollo y de dependencia económica y política del país. Fabrica castillos en el aire con su futura empresa «Sotero Chicken» (en realidad una pequeña granja de pollos), lo cual le conduce, inevitablemente, al fracaso. El subdesarrollo encierra no sólo lo económico y tecnológico; se refleja también en la visión del mundo y las limitaciones personales de los que viven sus consecuencias:

Intentando ayudar, el señor Flores le habló entonces de un muchacho del Cuerpo de Paz que andaba por ahí dedicado a lo mismo y a quien 
todo el mundo consideraba como casi un experto, y el teniente Sotero, aunque a regañadientes, accedió a visitarlo... La envidia y la rabia, sin embargo, le impidieron dialogar con él, pues el teniente no podía comprender por qué diablos, con menos medios, el americano había logrado levantar un plantel de varios miles de pollos sin apenas tropiezos, mientras que ellos... no acababan de encontrar el secreto a la cosa... ¿Qué carajo le estaba sucediendo a la incipiente industria? ¿Era que no había forma de sacar adelante ningún proyecto, por bien intencionado que fue ra, por mucho que se trabajara, en aquel infierno de país? (pp. 303-304).

La columna de humo negro que salía del dichoso agujero, producto también de la basura producida y de los excrementos (cuya utilización comercial ni siquiera llegó a considerarse) no dejó entonces, y durante seis largos días, de elevarse y de impregnarlo todo con el agrio olor de la carne quemada. Las aves, en efecto, continuaron muriéndose a una velocidad absurda ante la mirada idiota de Sotero, que contemplaba el espectáculo sin comprender por qué, ni cómo, sus sueños acababan de manera tan desagradable y azarosa (pp. 384-385).

Completamente hundido, Sotero, al final, es un hombre derrotado que considera «aquella inmensidad de simple nada que era su vida ahora» como las cenizas de sus aves quemadas.

El teniente es incapaz de ir más allá de las limitaciones del sistema cultural que representa; Altagracia Valle intenta comprenderlo y lo hace en una serie de capítulos que recuerdan y analizan el pasado. Como los demás, ella y su familia dejaron un lugar para encontrar la felicidad en otro: dejaron «la tierra», en Macorís, para ir a la capital. Altagracia representa otra generación de mujer, la que depende de su esposo para lograr el bienestar y la posición social. Todo lo pierde, pues, al morir él y al dejarla con un hijo que prefería emigrar antes que seguir viviendo en un país donde «todo continuaba igual» después de la muerte de Trujillo.

Quizás porque en el fondo yo pienso que es necesario resignarse, amoldarse a esa verdad y luchar como lobos para salir a flote, y él, en cambio, continúa creyendo que si por una parte toda lucha es, en efecto, inútil, resignarse, por otra, es claudicar. Por eso se me ha ido: no le quepa a usted duda (p. 214).

Figura nostálgica y estática (todos sus capítulos toman lugar el mismo día), sus retrospecciones mantienen vivo el pasado. De la misma manera lo hace la organización del texto, con sus interrupciones, pausas y regresos. En una lectura consecutiva de la novela el lector debe responder a la ruptura del hilo narrativo y hacer memoria de capítulos anteriores. 
Vergés parece reconocer, como otros escritores modernos, las limitaciones de la narrativa cronológica y comparte con ellos una visión de la historia que rechaza el concepto ingenuamente lineal: «History moves - but only as a delayed and displaced trajectory, through a series of social formations or ensembles. It develops by means of a series of breaks, engendered by the internal contradiction specific to each mode» ${ }^{12}$.

Pero, además, tomando en cuenta el contexto de la obra, el hecho de recordar en un país como la República Dominicana, donde la memoria colectiva de los años trujillistas y de todo lo que eso representaba se ha tratado de borrar, es una necesidad dura pero obligatoria. Precisamente es eso lo que indubablemente le fascinó e inspiró a Vergés de la época posterior a la muerte del tirano, una época en que muchos (no todos -Paolo, el joven amigo de Freddy y el único que lucha contra el sistema, muere-) creyeron que, con su desaparición y la de sus herederos, todo automáticamente cambiaría:

Todo lo negativo imaginable quedaba relegado, por arte y magia de no se sabe qué espontáneo maniqueísmo, al período histórico que acababa de morir, en tanto que los valores contrarios se pensaban como una consecuencia natural de esa muerte, como una especie de substancia mágica que surgiría del aire para llenar las casas, el corazón, la mente de gobernantes y de gobernados (p. 76).

Para desmitificar la historia hay que recordarla y reconocerse en ella si de alguna manera se espera comprender el presente y cambiar el futuro. $\mathrm{Y}$ así, el «diagnóstico colectivo» que es la narrativa dominica contemporánea es un justo y necesario proceso por parte de sus escritores que quieren convertir la «literatura de los derrotados» en la de los «herederos» y dejar de ser exiliados en su propia tierra, pues citando otra vez a Carew, «sólo cambiando nuestro mundo podremos heredarlo, y sólo heredándolo podremos poner fin a nuestro exilio interno y externo» ${ }^{13}$.

${ }^{12}$ Cita de Stuart Hall en «Ideology, Fiction, Narrative», de Terry Eagleton, en Social Text, 2 (verano 1979), p. 72.

${ }^{13}$ Carew, p. 44. 


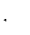

